\title{
DECOMPOSITION OF EEG SIGNAL USING WAVELET TRANSFORM
}

\author{
Khushbu Vyas ${ }^{1}$ \\ ${ }^{l}$ M.E. Student (Control System), Electrical Engineering, M.B.M. Engineering College Jodhpur, Rajasthan, India
}

\begin{abstract}
Epileptic seizures are manifestations of epilepsy. The detection of epileptic form discharges in the EEG is an important component in the diagnosis of epilepsy. Around $1 \%$ of the total population of the world is suffering from this problem. The present works aim at the classification of the EEG pattern we need to decompose it into different level.Decomposition is done using Daubechies wavelet order $8(\mathrm{db8})$ transform which is very popular and efficient technique. Once the decomposition is done into different levels, we get subbands of signal and called as brain waves (delta, theta, alpha, beta, and gamma). Important features such as minimum, maximum, mean, standard deviation, median has been calculated. These features will be used for the classification.
\end{abstract}

Keywords: Epilepsy, (Electroencephalography)EEG, Brain waves, Wavelet transform, Feature extraction

\section{INTRODUCTION}

Detection of Epilepsy Seizure is playing main role in today's time because of the seizure activity in EEG segment is crucial for the localization so in this paper signal is decomposed in certain frequency bands for the observing epilepsy seizure, since the nature of EEG signal is nonstationary so wavelet transform method has been used for the efficiency of proposed approach. Some features have found in certain frequency bands and it is expected that is to be used for the classification of epilepsy seizure.

\section{EPILEPSY}

Epilepsy Seizure is a sudden rush of electrical activity in the brain that is difficult to recognize [1]. The word 'epilepsy' is derived from the Greek word epilambanein.Epileptic seizures can be categorized [2] as generalized seizures and Partial seizures. Classification of seizure is shown in following figure 1 .

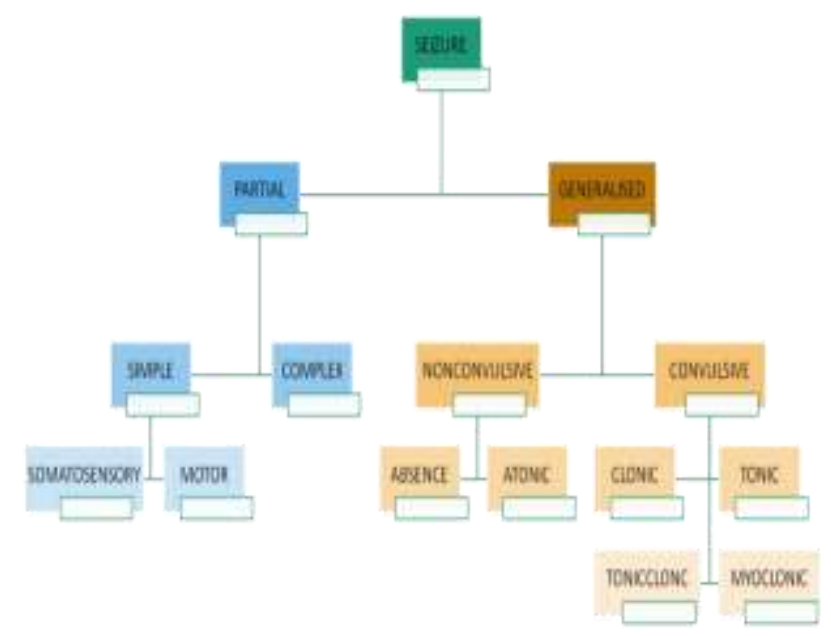

Fig 1: Seizure Classification
Generalized seizures involve most areas of the brain whereas focal (partial) seizures originate from a circumscribed region of the brain, often called epileptic foci.

\section{EEG}

Through the EEG[3] we can monitor the brain activity and diagnose the neurological disease, especially for the early detection of epileptic seizure activity. There is a specific method to use the EEG electrodes placed at various positions on the scalp of a patient. With the help of EEG we get the Brain waves of different frequency ranges associated with the different stages of sleep[4]. This is firstly applied to humans in the 1920 s by German neurologist Hans Berger (Jung \& Berger, 1979), EEG is a non-expensive, noninvasive and completely passive recording technique.

\subsection{EEG Dataset}

The data set [5] used in the study is publicly available online by Dr. Ralph Andrzejak of the Epilepsy Center at the University of Bonn, Germany .It includes both healthy and epileptic EEG dataset. The dataset includes five subsets (denoted as $\mathrm{O}, \mathrm{Z}, \mathrm{F}, \mathrm{N}$ and $\mathrm{S}$ ) each containing 100 singlechannel EEG segments, each one having 23.6-second duration and 4096 samples. 

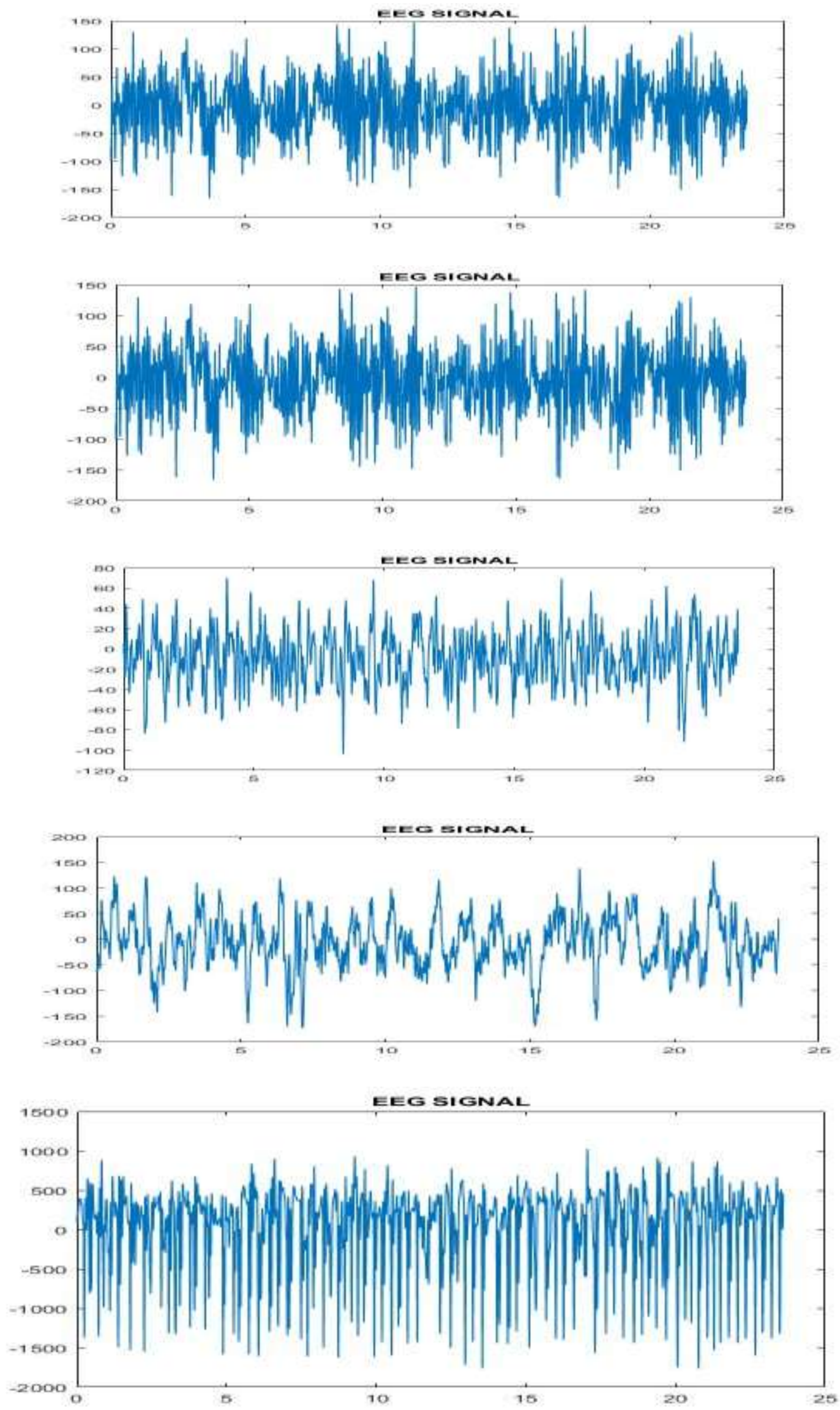

Fig 2.1: EEG signal in time domain from set $\mathrm{O}, \mathrm{Z}, \mathrm{F}, \mathrm{N}, \mathrm{S}$ respectively. 


\subsection{Methodology}

This work aims at decomposition of EEG signal using Daubechies wavelet transform [5]db8, which decompose EEG signal into 8 levelcomes.Then based on feature

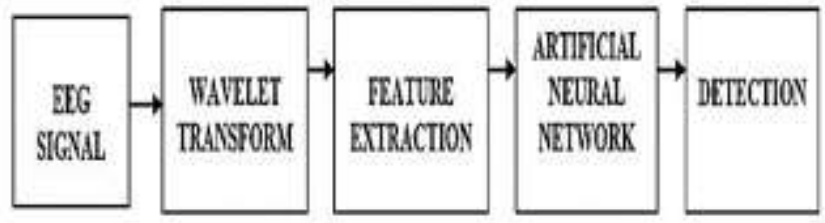

Fig 2.2: Block diagram of Methodology

extraction like min, max, mode, median of decomposed level can be used for the trained the neural network further classification of EEG signal as seizure

\section{WAVELET TRANSFORM}

The wavelet transformation analyzes the signal at different frequency bands, with different resolutions by decomposing the signal into approximation and detail coefficients [6].

$$
\begin{aligned}
& W_{\Phi}(j, k)=\sum_{m} h_{\Phi}(m-2 k) W_{\Phi}(j+1, k) \\
& W_{\Psi}(j, k)=\sum_{m} h_{\Psi}(m-2 k) W_{\Phi}(j+1, k)
\end{aligned}
$$

$W_{\Psi}(j, k)$ and $W_{\Phi}(j, k)$ are the coefficientsin discrete wavelet transform. The discrete wavelet transform (DWT) provides sufficient information both for analysis and synthesis of the original signal, with a significant reduction in the computation time.

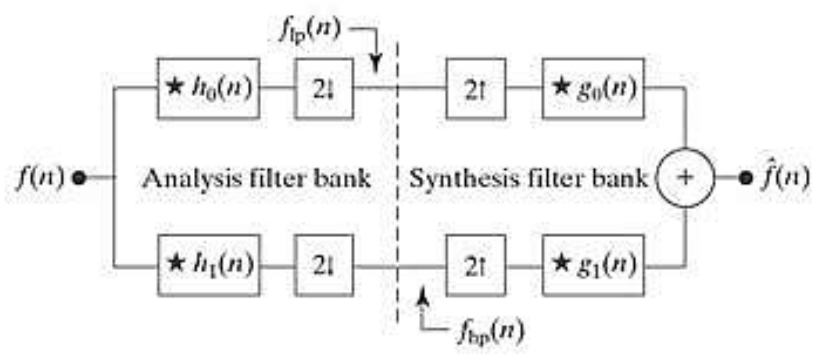

Fig 3.1: Analysis and Synthesis Filter Banks

where $\mathrm{g}[\mathrm{n}]$ is the highpass, $\mathrm{h}[\mathrm{n}]$ is low pass filter, and $\mathrm{L}$ is the filter length (in number of points). That the two filters are odd index alternated reversed versions of each other.Lowpass to high pass conversion is provided by the ($1)^{\mathrm{n}}$ term filterssatisfying this condition are commonly used in signal processing, and they are known as the quadrature mirror filters $(\mathrm{QMF})$

$$
\begin{aligned}
f_{\text {high }}[k] & =\sum_{n} f[n] \cdot g[-n+2 k] \\
f_{\text {low }}[k] & =\sum_{n} f[n] \cdot h[-n+2 k]
\end{aligned}
$$

The oldest and most known is MALLAT or pyramidal algorithm is used in which two filters smoothing and nonsmoothingare constructed from wavelet coefficients and those filters are recurrently used to obtain data for all the scale.

\section{CONCLUSION}

Decomposition of EEG signal into 8 level was done, in Feature Extraction process features like min, max, mean, median, standard deviation of the decomposed signals were extracted.

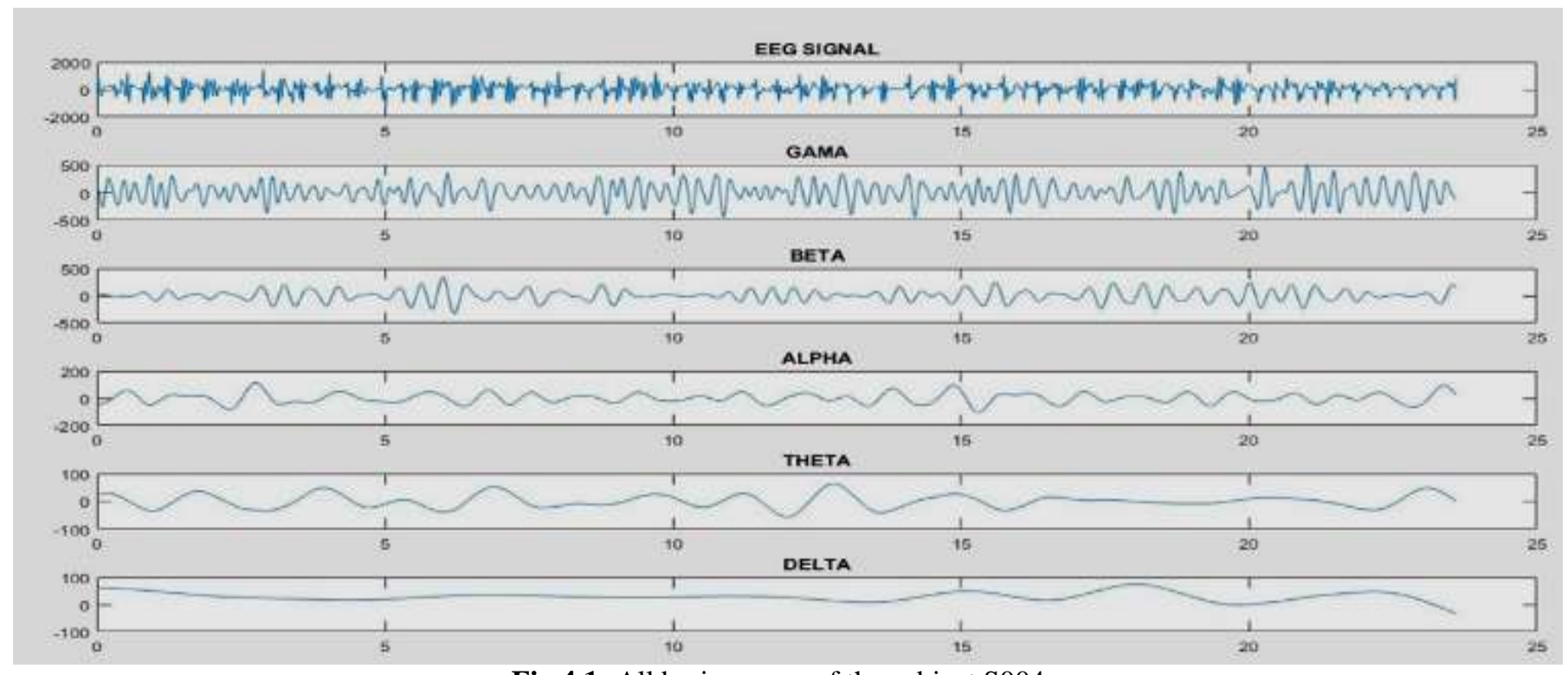

Fig 4.1: All brain waves of the subject S004 


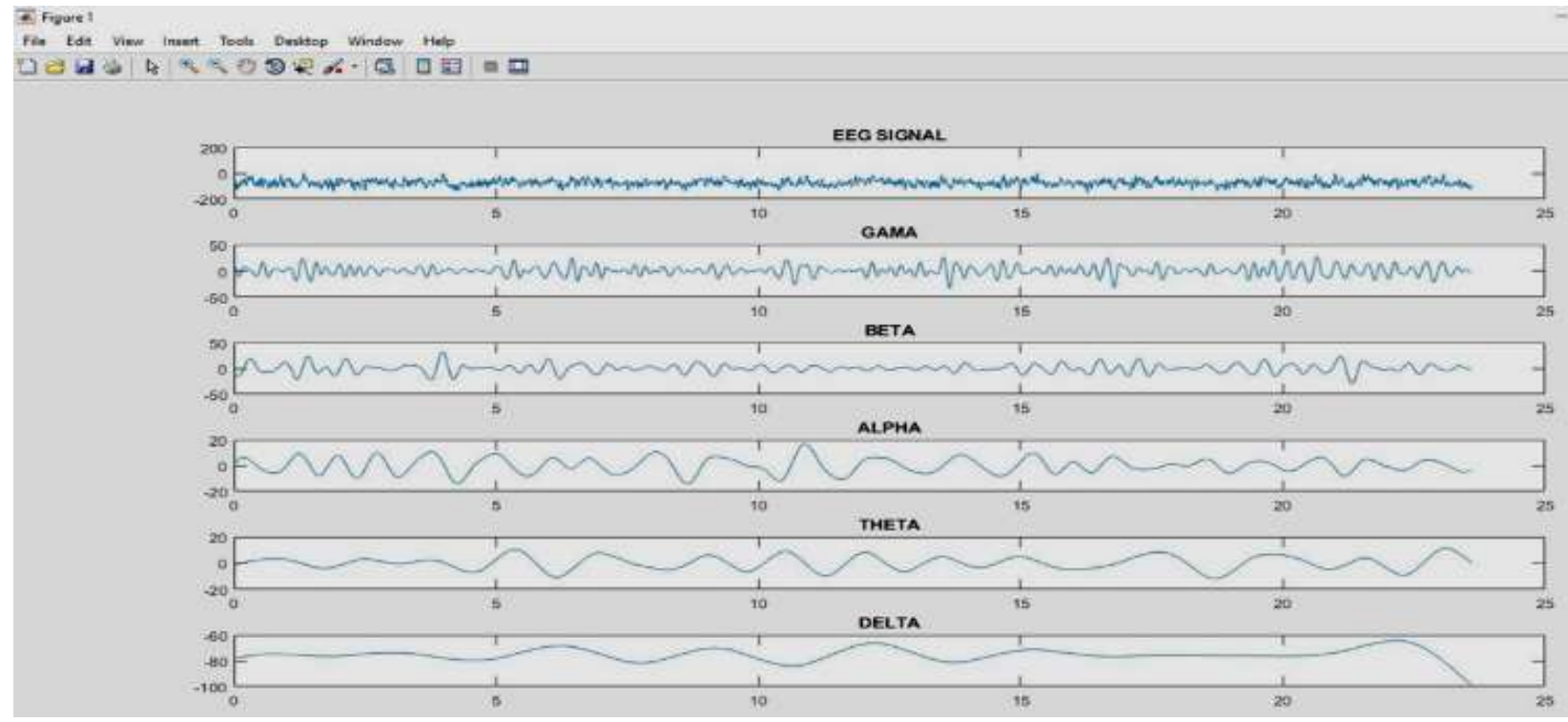

Fig 4.1: All brain waves of the subject Z038

It has been determined that the abrupt changes in the alpha and beta waves of the sets will be having a major seizure and the signals without abrupt changes in their frequency bands will be normal.[7]

Table 1: Feature from the Delta wave of following subjects

\begin{tabular}{|c|c|c|c|c|c|}
\hline EEG Signal & Min & Max & Mean & $\begin{array}{l}\text { Media } \\
n\end{array}$ & Std \\
\hline $\begin{array}{l}\text { Normal(S004 } \\
\text { ) }\end{array}$ & $\begin{array}{l}- \\
164.87 \\
4\end{array}$ & $\begin{array}{l}48.79 \\
2\end{array}$ & 5.267 & 7.88 & $\begin{array}{l}20.7 \\
5\end{array}$ \\
\hline $\begin{array}{l}\text { Epileptic } \\
\text { (Z038) }\end{array}$ & -98.637 & $\begin{array}{l}- \\
64.43 \\
7\end{array}$ & $\begin{array}{l}- \\
75.26 \\
9\end{array}$ & $\overline{-} 75.762$ & $\begin{array}{l}4.62 \\
9\end{array}$ \\
\hline N099 & -28.599 & $\begin{array}{l}22.02 \\
1 \\
\end{array}$ & -0.222 & -0.381 & $\begin{array}{l}7.88 \\
0 \\
\end{array}$ \\
\hline O097 & -19.78 & $\begin{array}{l}10.94 \\
3\end{array}$ & -5.048 & -5.182 & $\begin{array}{l}6.72 \\
0\end{array}$ \\
\hline F099 & -15.286 & $\begin{array}{l}14.31 \\
2\end{array}$ & -8.587 & -8.907 & $\begin{array}{l}3.63 \\
8\end{array}$ \\
\hline
\end{tabular}

\section{REFERENCES}

[1]. N. Sivasankari, K. Thanushkodi, and H. K. Naidu, "An Extensive Review of Significant Researches on Epileptic Seizure Detection and Prediction using Electroencephalographic Signals," Advances in Biomedical Research, pp. 330-353, 2010

[2]. Engel, Jr, J. and Pedley, T. A., Epilepsy: A Comprehensive Text-book, Lippinottc-Ravon, Philadelphias,Pennsylvania, 1997.

[3]. Joseph D. Bronzino(2006), The Biomedical Engineering Handbook Third Edition, Medical Devices and Systems, CRC press.

[4]. MirceaSteriade (2004), Neuronal substrate of sleep and epilepsy. The Pitt Building, Trumpington Street, Cambridge, United Kingdom 2004.
[5]. EEG Time Series, October 2012, Available http://www.meb.unibonn.de/epileptologie/science/physik/ee gdata.html

[6]. wavelet transform an introduction by P.M. Bentley and J.T.E. McDonnellieeexplore.ieee.org/document $/ 311360 /$

[7]. Suhanya.S 1, Manimegalai.P2 -- (March-2012), DETECTION OF EPILEPSY DISORDER IN EEG SIGNAL, International Journal of Emerging trends in Engineering and Development Issue 2, Vol.2

\section{BIOGRAPHIE}

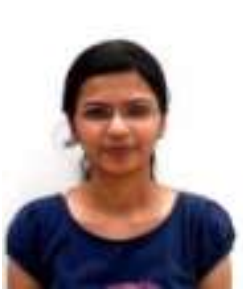

Khushbuvyas was born in Rajasthan, India in 1990. She received B. tech degree in ECE in 2012 from RTU Kota. Currently Submitted thesis on "Decomposition of EEG signal using wavelet transform" in MBM Engg. College for Master of Engineering. 